\title{
The start of caring for an elderly dependent family member: a qualitative metasynthesis
}

\author{
Lourdes Moral-Fernández *iD, Antonio Frías-Osuna, Sara Moreno-Cámara, Pedro A. Palomino-Moral \\ and Rafael Del-Pino-Casado
}

\begin{abstract}
Background: The family often takes care of an elderly person who suddenly becomes dependent. This greatly affects different aspects of the caregivers' lives. The aim of this study is to explore the initial experiences, during the first year of care, of persons who suddenly become caregivers for elderly dependent relatives.

Methods: A search in CINAHL, PsycINFO, WOS, Medline, and Scopus and a metasynthesis of qualitative research were conducted including 19 articles.

Results: Three categories were developed to explain the process of becoming a caregiver 'taking on the role' (life changes, uncertainty and confusion, and acceptance or resistance); 'beginning to realise' (new needs, impact, and appraisal); and 'implementing strategies' (seeking help and self-learning, reordering family and social relationships, solving problems, and devising strategies to decrease negative emotions and stress).

Conclusions: The synthesis provides a comprehensive understanding of the experience of becoming a caregiver in order to help health-care professionals to adapt care plans to this situation.
\end{abstract}

Keywords: Family caregiver, Qualitative, Metasynthesis, Initial, Elderly dependent

\section{Background}

The world population has been experiencing a growth in the numbers of older people since the mid-twentieth century, a trend which will no doubt continue through the twenty-first century [1]. This increase in life expectancy is one of the greatest human achievements of recent times, but the fact of living longer carries the likelihood of suffering chronic and disabling diseases that involve increasing dependency [1].

At present, public policy offers low levels of formal long-term care provisions in most EU countries [2, 3]. As a result, family and friends-and especially womenare mitigating this shortcoming. Thus, the figure of the family caregivers appears, as 'a non-professional person who provides primary assistance with activities of daily living, either in part or in whole, towards a dependent person in his/her immediate circle' [2].

* Correspondence: Imf00006@red.ujaen.es

Department of Nursing, School of Health Sciences, University of Jaén,

Campus Las Lagunillas, s/n, 23071 Jaén, Spain
Taking care of a dependent person involves changes and assumption of new responsibilities by the caregivers, which change their lives significantly. They have to deal with activities of daily living that they previously did not have had to do [4]. Thus, many aspects of caregivers' physical and mental health, as well as their social and family lives are affected negatively by their caring role [5], causing them problems with their physical health, relationships, personal well-being, and finances [6, 7].

The pathologies that generate dependency can appear progressively or suddenly. The type of appearance of the illness affects the adaptation process of the caregivers [8]. Progressive appearance diseases make the adaptation process easier because of the smooth and gradual onset of the disease. Abrupt or acute appearance diseases require an immediate adoption of the task of caring, and thus, these bring a more sudden change for the caregivers and make the adaptation process more difficult [9]. In this adaptation process, several aspects are

(c) The Author(s). 2018 Open Access This article is distributed under the terms of the Creative Commons Attribution 4.0 International License (http://creativecommons.org/licenses/by/4.0/), which permits unrestricted use, distribution, and 
involved, among which are the needs, expectations, consequences, and feelings of family caregivers [8].

Research shows that the initial stage of caregiving is the worst, especially when the relative has become suddenly dependent [10].

Helping caregivers to adapt to their role may diminish the negative consequences of care $[11,12]$. In order to help this adaptation by implementing the right caregivers' interventions, it is essential to know the process and characteristics that surround this change.

There are few studies that attempt to clarify the phases that a person goes through as a family caregiver at the beginning of her or his caregiver role, and those that do involve either theoretical research $[13,14]$ or they focus on specific issues and specific areas [15-18].

Thus, we have perceived a need for a reinterpretation of the whole process of suddenly taking on a caregiver role. The knowledge and in-depth and holistic understanding of the caregivers' experiences in the early stages will allow us to understand and identify the elements and dimensions involved in the process of becoming a family caregiver. With this, health-care professionals could be better informed and offer interventions that are better adapted to the situation faced by caregivers at the beginning of their caring role, ensuring the well-being of the caregiver and, therefore, of the care recipient as well.

Because there are several qualitative studies that offer an in-depth analysis of the beginning of the caring role, we decided to conduct a qualitative metasynthesis in order to expand the transferability of the results from this research. The aim of this metasynthesis is to explore the experiences during the early stages of a person becoming the caregiver of an elderly dependent relative who has suddenly experienced an acute illness. The specific aims were to identify qualitative research in this area, and through synthesis of the study findings, describe the characteristics and the process of becoming a caregiver.

\section{Methods}

\section{Design, setting, and sample}

We present a qualitative metasynthesis, following the procedures of Sandelowski and Barroso [19]: (a) literature search, (b) quality assessment, (c) analysis of findings, and (d) synthesis of findings. We examined the study findings using constant comparative analysis, and we coded, compared, and sorted conceptual categories, attempting to interpret each category in relation to each other across studies.

\section{Literature search}

To identify qualitative studies, we formulated a comprehensive search carried out from May 2018 to June 2018. To find all relevant studies, we used a multifaceted search strategy with several search strings without time limit for inclusion of the publications. In spite of the difficulties involved in the search for qualitative studies because of the richness and expressive variety of the titles of qualitative research, different alternative terms were searched for the description of the research subject (transition, new or become), following the recommendations of McKibbon, Wilczynski and Haynes [20] and Evans [21] to maximise sensitivity. MeSH (Medical Subject Headings) terms were also added where possible, in order to encompass the most widely used database search such as Medline (caregiver * or carer *).

The search string used was: (Caregiv* or carer*) AND (new caregiv* or become caregiv* or transition in caregiv* $^{*}$ or new carer* or become carer* or (transition and carer*)) AND ((("semi-structured" or semistructured or unstructured or informal or "in-depth" or indepth or "face-to-face" or guide or guides) AND (interview" or discussion" or questionnaire*)) or ("focus group" or "focus groups" or qualitative OR ethnograph" or fieldwork or "field work" or "key informant" or "interviews as topic" or "focus groups" or narration or qualitative research or "personal narratives as topic")).

The five databases searched were: CINAHL, PsycINFO, WOS, Medline, and Scopus. We manually searched the bibliographies of the selected articles to capture relevant research articles that fell outside the identified search terms utilised, through which four more manuscripts were added.

The search resulted in a total of 5102 results, of which 3037 were duplicates. Of the 2065 remaining records, 1603 were not relevant to the topic and 462 could fit the inclusion criteria according to the title and/or abstract. The main author reviewed the complete texts of these 462 articles and discarded 447 (73 studies that were not qualitative one, 94 because they did not focus on family care, 101 because they did not study dependent elderly people and 179 because the researches did not occur at the beginning of care). As a result, a total of 15 articles that met the inclusion criteria were selected to be included in the metasynthesis. In addition, four more studies were included by reviewing the references of full texts revised (Fig. 1).

\section{Study selection}

Due to the difficulty of identifying relevant research by keyword searching alone, we manually searched for all the studies which met the inclusion criteria. Papers were reviewed first by title, then by abstract, and finally by full text whenever it was necessary. Inclusion criteria for the metasynthesis were: (a) new primary caregiver (b) caring for less than 1 year (c) for a dependent elderly relative who has suffered an abrupt or acute disease causing dependency; (c) research using qualitative methodology. 


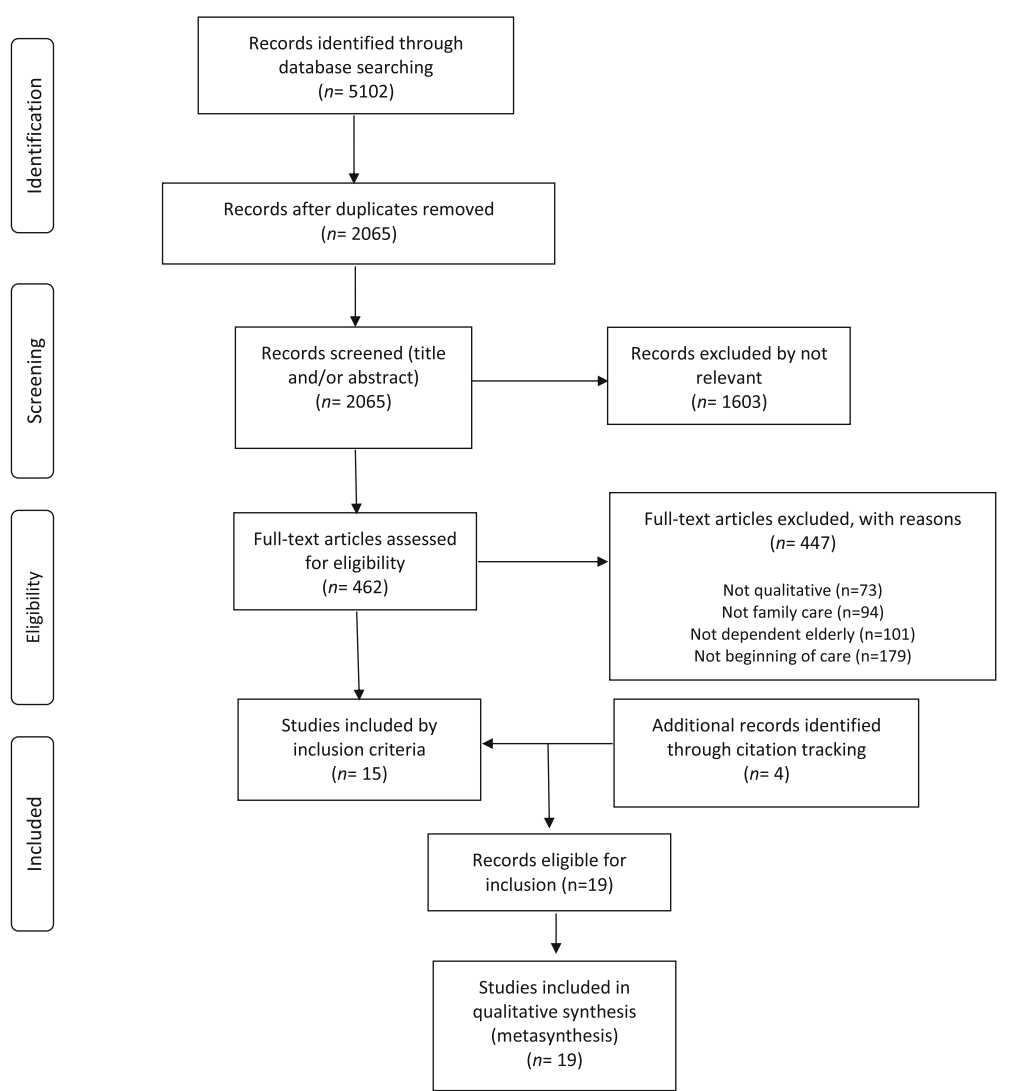

Fig. 1 PRISMA (*) flow diagram of the review process. $\left(^{*}\right)$ Moher D, Liberati A, Tetzlaff J, Altman DG, The PRISMA Group. The RISMA statement for reporting systematic reviews and meta-analyses of studies that evaluate health care interventions: explanation and elaboration. J Clin Epidemiol. 2009; 62: 1006-1012

\section{Quality appraisal}

According to Sandelowski and Barroso [19], although quality should not be a criterion used to exclude studies, it should be included in the comparative analysis of the design features of each study. For this, we used the Critical Appraisal Skills Programme (CASP) - Qualitative [22], following a prescriptive and comprehensive checklist appropriate for metasynthesis and widely extended in this type of research [23]. The tool consists of 10 questions relating to rigour and relevance, with an assessment system of "yes", "no" or "can't tell". This evaluation of the evidence is based on subjective and judicious discussions about the quality of the recovered evidence. The first two questions (yes / no) are mandatory questions. If the answer is affirmative in both questions, the remaining questions are assessed. The following seven questions are about the research design, data collection and analysis. The last question is about clinical applicability, so we did not use this question.

\section{Data extraction}

After the localisation and selection of the studies, the extraction of the findings from the primary sources was started through manual extraction in each manuscript, including the specific results presented by the researchers as subjects and the dialogues of the participants in the original. This allowed us to reduce the bias of erroneous extraction of data from primary sources [24]. To classify and summarise the studies, the descriptive data of each study were extracted, and the information of each article regarding its design and the characteristics of the sample were recorded in a customised form.

In total, we analysed interview fragments of 393 family caregivers, whose verbatim comments appear in the 19 included articles and are transcribed in 59 pages.

\section{Data analysis}

After the abstraction of data, two of the authors performed the analysis individually, developing categories and coding the data. A dynamic and iterative process of thought, induction, interpretation, theorisation and reflection (chosen against the method of integration and aggregation) were performed. The information was extracted and interpreted, and the findings were obtained through the taxonomic organisation of categories and 
subcategories, following axial, selective, in vivo, or imported encoding of the same. Everything was done with the help of memos, which arose from the writing of theoretical ideas about codes and their emerging relationships in the coding process [25].

Findings of the research have been introduced in the version 11 NVIVO software, developed by Qualitative Solutions and Research, which allows for the coding of texts in a series of categories that classify dimensions, properties and attributes. The study method and process are presented in detail below.

After a thorough reading of the interview fragments, 693 references resulted and 169 total codes were identified with the highest level of disaggregation. Secondly, we established the characteristics and relationships of the categories and subcategories grouped according to similarities and differences. As a result of this process, and after the consensus of the two researchers involved in the analysis, a total of 16 categories and 10 subcategories emerged.

Finally, a consensus was made between the two researchers involved in the analysis, in order to make the qualitative synthesis, guided by the grounded theory approach $[26,27]$ through the repeated use of the constant comparative method, for which we looked for similarities and differences in the information available. The memorandums were significant in the process of constant comparison, allowing for the design of the emergency map, and the identification of the concepts and their relationships.

To synthesize the categories, the research team relied on the discourses of the caregivers, repeatedly mentioning the existence of different stages of care. These discourses revealed an initial stage triggered by the illness of his relative and the great change that occurred in all aspects of his life as they began to become caregivers, causing feelings of uncertainty and confusion. From here, caregivers develop different ways of coping, leaving attention, avoiding facing or accepting it, beginning to realize this way of their new role as caregiver. During this phase, caregivers manifest new needs, different consequences of care and re-evaluate their situation with the intention of normalizing it. At this time, the caregivers implement strategies according to their resources, the relationship with the dependent person, the way in which they face their role as caregivers and the circumstances that surround them. Thus, to synthesize the findings, a process of becoming a caregiver with different moments and phases of care was proposed (Fig. 2).

In the last phase of the metasynthesis process, we determine a general conceptualization of the analysis among the researchers of the study, the adjustments of the matrix of each category, and the subcategory and the groups in an inductive manner. The findings were reduced in the coding process, regrouped into ten subcategories integrated into broader categories. This process was carried out according to the relationships of the axis and the care phases appeared in the caregivers' discourses, and finally three final categories were obtained. To complete the qualitative synthesis, the topics were discussed in several categories by the entire group and a diagram was made with the results of the process of becoming a family caregiver of an elderly dependent.

\section{Validity}

As suggested by Sandelowski and Barroso [19] or Maxwell [28], several procedures can be employed to
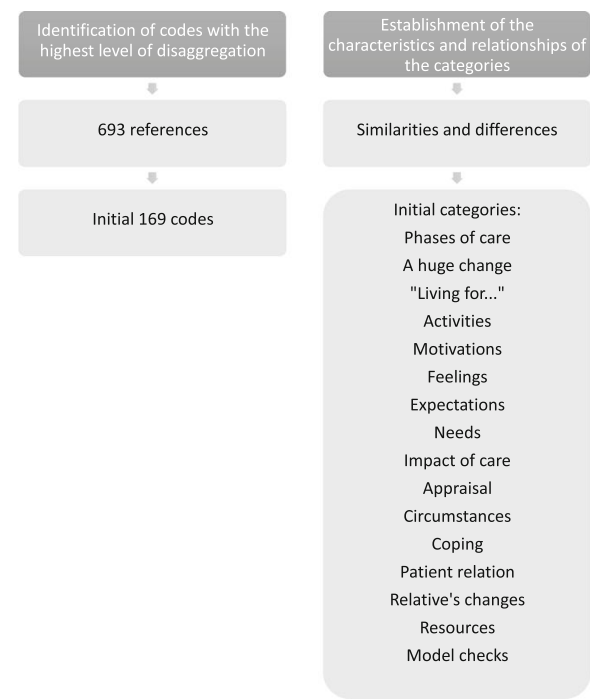

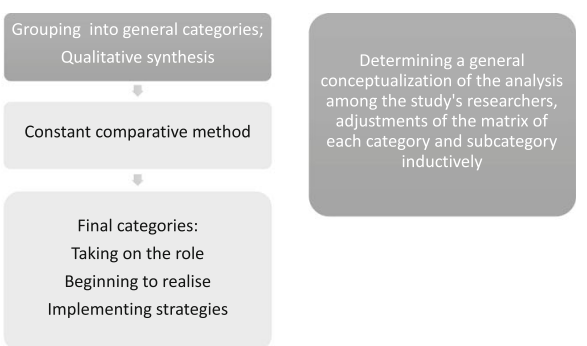

Fig. 2 Analysis process 
improve the descriptive, interpretive and theoretical validity of qualitative research integrations.

The descriptive validity was maintained through a thorough search of research related to the subject of study and description of the information of each article included in this metasynthesis, as well as by a CASP quality score assigned by the research team.

Interpretive validity was maintained by team members who analysed the results of the individual studies and integrated them into consensus. In addition, notes were taken during meetings of the research team to maintain an audit trail in decision-making.

The theoretical validity was related to the theoretical constructs that were developed during the study, beyond the description and the interpretation of the primary studies.

\section{Results}

The 19 articles included a total of 393 family caregivers. Most caregivers were women (77\%), usually wives and daughters, of various nationalities and with an average age of approximately 50 years. The people cared for were dependent elderly persons (average age of 72 years), with different types of health conditions: stroke, cancer, hip fracture, brain injury, accident, sepsis and transplant.

Of the 19 articles (Table 1), one was written in Portuguese but had translations in English and Spanish, one was written in Spanish, and the others were all written in English. Geographically, five of the articles were from the United States, one from Canada (Ontario), two from South America (Brazil), seven from Europe (Italy, Scotland, England, Spain and Portugal), two from Asia (China), and two from Australia.

The different methodological approaches found were: (a) phenomenological design (three works); (b) content analysis (one); (c) thematic content (three); (d) ethnographic design (one); (e) grounded theory (four); (f) constant comparative analyses (two); (g) theory based on data (one); (h) Van Manen's approach (one); and (i) method used not specified (three). The methods of collecting the information have been interviews and focus groups.

Regarding the methodological quality of the included studies, we found some weaknesses in the following questions: justification of the design used, adjustment of data collection method with the objective and methodology, and the analysis of authors' role in the research (Table 2).

First, the appearance of different moments or stages of care in the caregivers' discourses helped the researchers to classify the different categories around different stages of care: "It has different stages, they change and each stage has its good and bad things. You have to adapt as you can to each situation" [29].
According to this fact, and following the analysis, three categories appeared that involved the process of becoming a caregiver: 'Taking on the role' (including life changes, caregivers' uncertainty and confusion, and caregivers' acceptance or resistance); 'beginning to realise' (including caregivers' new needs, impact, and appraisal), and 'implementing strategies' (including seeking help and self-learning, reordering family and social relationships, solving problems, and devising strategies to decrease negative emotions and stress) (Fig. 3).

\section{Taking on the role}

Caregivers feel an initial shock associated with the illness and disability of their family members. Their lives are turned upside down due to the changes associated with becoming a caregiver [29-31].

They mention the new situation that they have to assume and describe the day of onset of their family member's illness as crucial to their lives and as unpredictable [32-34].

The transition in moving from the hospital to the home tends to be harder than they expected, as it contrasts with the joy they experience after discharge and being in their usual environment, where they find instead a concern and lack of preparation to provide necessary care to their family member [34-36].

\section{Life changes}

The changes in the lives of caregivers when they face an imminent situation of dependence of a family member are very large, since in most cases the dependent person has hitherto led an autonomous life and now, due to an illness or acute problem, suddenly finds him- or herself in a situation of dependence [29, 36-38]. 'This cancer has been a total disruption of my life. Your whole life changes in 24 hours.' [30].

The caregiver must then leave his or her life aside and almost exclusively care for their relative. Normally, as the carers exercise their role, their daily activities are multiplied. As a result, caregivers have to cope with a huge amount of new responsibilities related to care.

\section{Uncertainty and confusion}

The changes and the assumption of new responsibilities of care cause diverse emotions for the caregivers, among which the following stand out: the uncertainty, the imprecision of the prognosis related to the illness, for the future that they have to face, and for the lack of information and preparation for the situation [32, 34, 37-41]. 'They just don't know-that is what is quite scary, it is the unknown. You just don't know what it is going to be like in a year's time... because... everybody is just so different.' [40]. 
Table 1 Summary of articles included in the metasynthesis

\begin{tabular}{|c|c|c|c|}
\hline $\begin{array}{l}\text { Author (year), } \\
\text { country }\end{array}$ & Purposes & Methods and sample & Main Results \\
\hline $\begin{array}{l}\text { Houldin (2007) } \\
\text { [30] } \\
\text { Philadelphia } \\
\text { (EEUU) }\end{array}$ & $\begin{array}{l}\text { To report on a descriptive study of patients } \\
\text { newly diagnosed with advanced colorectal } \\
\text { cancer. }\end{array}$ & $\begin{array}{l}\text { Semi-structured interviews to } \\
14 \text { carers and thematic } \\
\text { content analysis. }\end{array}$ & $\begin{array}{l}\text { Findings revealed three domains: Experiencing } \\
\text { total disruption of my life, Staying positive, and } \\
\text { Attempting to keep family and children's } \\
\text { routines as normal as possible. }\end{array}$ \\
\hline
\end{tabular}

Paiva et al. (2012) To discuss the relationship between the family

[31]

Río de Janeiro

(Brasil)

Plank et al.

(2012) [32]

Verona (Italy) and hospital discharge regarding manifestations, attitudes, feelings and practices.

To explore and understand the experience of new informal carers in Italy during the transition from hospital to home.

Grimmer et al. (2004) [36]

Australia

To describe the perceptions of people taking on a new or expanded caring role of an elderly patient recently hospitalised with a new or intensified health problem.

Teschendorf To describe informal cancer care provision et al. (2007) [41] from the perspective of the carer.

EEUU

Nahm et al. (2010) To explore informal carers' experiences with [37] Baltimore (EEUU) providing care to older adults over the first 6month trajectory of hip fracture recovery and their support needs.

Smith et al.

(2004) [35]

Glasgow

(Scotland)

Pereira and Rebelo-Botelho (2011) [38] Portugal

Greenwood et al. (2009) [40] London

(England)

The purpose of this qualitative study was to understand the lived experience of individuals taking on the role of informal adult carers after an unexpected event involving a relative.

To investigate the experiences of informal carers of stroke survivors over time.
Bakas et al.

(2002) [39]

Oklahoma

(EEUU)

Weng et al

(2011) [42]

Taiwan (China)
To determinate the self-reported needs, concerns, strategies, and advice of stroke carers during the first 6 months after hospital discharge.

To explore the stress experienced by the primary family carer of the living-related liver transplantation patient during the postopera tive stage.
Semi-structured interviews to 9 carers and theory based on data approach.

Findings reflected the categories: "Facing the unexpected," "Recognizing the need for care after discharge" and "Realizing one's importance in the recovery of the relative".

In-depth interviews and focus Family caregivers reflected their newly groups to 18 carers and a qualitative phenomenological approach.

Semi-structured interviews to 24 carers (method used not specified).

Focus groups to 63 carers and content analysis.

In-depth interviews to 10 acquired role; the recipient's condition; and the support they required. The core concept of 'being responsible for everything' seemed to be a recurring theme running through these three subject matters.

The study highlighted carers' perceptions of being unprepared for their new tasks, and their frustrations at the long-term and frequently significant changes to their lives brought about by assuming a caring role.

Providing supportive care introduced a balancing act in caregivers' lives as they attempted to address complex and overlapping roles. They felt alone in their decisions, were under-prepared for tasks they assumed, and tried to shield the care recipient

Management of hospital bills and transitions carers and phenomenological between care settings were especially approach.

burdensome. The caregiving situation was viewed as an opportunity to spend more time with their loved ones. Findings revealed unmet support needs expressed by caregivers of older adult hip fracture patients.

Semi-structured interviews to 90 carers and thematic data.

Unstructured interviews to 14 carers and Van Manen's approach.

Audio-taped in-depth inter views to 31 carers (method used not specified).

Initially most carers found that they lacked the knowledge and skills to care for the stroke survivor at home and so they had to learn how to obtain the information and assistance required. Carers had to adapt to the changes that stroke effected in the stroke survivor and seek alternative ways of securing the resources they needed for managing their lives.

Four main themes were identified: losing control over time, feeling alone, failing expectations and taking over someone else's life.

A central theme of uncertainty with a number of other interconnected themes were identified. Other themes including adopting routines and strategies, absolute and relative positives and questioning the future could be seen to both influence and be influenced by uncertainty.

Open questions by telephone Findings revealed five major categories of to 14 carers (method used not specified). caregivers needs and concerns: information, emotions and behaviours, physical care, instrumental care, and personal responses to caregiving

Face-to-face semi-structured Participant stress was caused by the gap interviews to 6 carers and the between expectations and primary caregiving matic content analysis. experiences. In particular, the five themes that were identified: unstable sentiment towards liver transplantation; entanglement of burden; non-synchronized family interaction; distance 
Table 1 Summary of articles included in the metasynthesis (Continued)

Author (year), Purposes Methods and sample Main Results

country

Silva-Smith

(2007) [43]

Colorado

(EEUU)

Brereton and

Nolan (2002)

[45] Sheffield

(England)
To describe the process associated with preparing for and beginning a new caring role following a family member's stroke.

To gain a better appreciation of the needs of new carers of stroke survivors and to consider how these needs change as their role develops.
Shyu (2000) [46]

Taiwan (China)

Shaw et al.

(2013) [33]

Sidney (Australia)
This study explored the needs of family carers during the transition from hospital to home.
Face-to-face interviews to 16 carers and constant comparative analysis.

Semi-structured telephone interviews to 15 carers and constant comparative analysis. surgical intervention to (1) identify their unmet supportive care needs and (2) investigate how family carers perceive their role during this time.

Rodrigues et al (2013) [44] Sao Paulo (Brasil)

Abrahamson et al. (2017) [34] England

Giosa et al. (2014) [47] Ontario (Canada)

Moral-Fernández et al. (2018) [29] Jaén (Spain)
To examine the transition of care in families caring for elderly persons who suffered the first episode of a cerebrovascular accident.

To explore the experiences of individuals who have had a severe traumatic brain injury (TBI) and their carers in the first month postdischarge from in-patient rehabilitation into living in the community.

\section{To explore informal family caregiver} experiences in supporting care transitions between hospital and home for medically complex older adults.

To describe the initial process through which people who imminently become caregivers of a dependent elderly relative.
Interviews to 10 carers and instrumental ethnographic approach. 10 patients and nine carers, and thematic analysis. theory analysis.

In-depth interviews to 11 caregivers, and grounded theory analysis.
Audio-taped interviews to 12 carers and grounded theory analysis.

Interviews to 14 carers and grounded theory analysis. from the healthcare professional; and concern about the protector role function.

Restructuring life for caregiving was associated with five dimensions: daily life, managing multiple roles, relationship with the stroke survivor, future hopes and plans, and time for self.

During the initial period carers engage in a number of different 'seeking' activities in order to try and ensure that they feel competent, confident and safe to provide care and that they understand the likely future demands they may face. Rather than being facilitated by staff, carers' efforts often go unnoticed or are overlooked, resulting in carers feeling that they are 'going it alone'.

Role tuning was the process used by caregivers and care receivers to achieve a harmonious pattern of caregiving and care receiving during the transition from hospital to home.

Family caregivers reported significant information and support needs, their distress was exacerbated by a lack of patient care knowledge. Access to support was limited by caregivers' lack of understanding of the health system and they view their role as part of their family responsibility.

Semi-structured interviews to

Semi-structured interviews to 12 caregivers and grounded
They describe the care process for the dependent elderly person, strategies for the care process and impact and acceptance of the limitations.

Many patients and carers felt unsupported in the inpatient phase, during transitions; they struggled to accept a new reality of changed abilities, loss of roles and loss of autonomy, and early experiences post-discharge exacerbated fears for the future.

They describe the theory "building capacity to care", which involves assessing a caregiver's unique family situation to tailor and provide relevant information, education, and training.

An initial phase of changes, in which the caregiver assumes new activities; a second phase full of emotions, in which the needs and consequences emerge; and a third phase that emphasises acceptance as a coping strategy and uncertainty as an expectation of the future.
Although uncertainty is present both in the present and in the future, family caregivers experience different feelings such as: concern about the care situation they must assume; suffering from seeing the discomfort of the family member they are caring for and the change they have undergone; impotence for not being able to do more or take better care of them; or guilt for failing to perform this task as they would consider appropriate or even for wanting to end that situation in any way $[29,32,33,38,41]$.

\section{Acceptance or resistance}

Given all the problems and needs that family caregivers have, they show different ways of tackling the changes that occur when they begin caring for their relatives. Among these ways that can be adopted of tackling the issue, we find there is generally acceptance of or resistance to the care situation [31-33, 35, 40, 41].

However, other family caregivers are not located on either end, and they underline the lack of knowledge about how to deal with this situation [35]. 'You have to 
Table 2 Critical Appraisal Skills Program

\begin{tabular}{|c|c|c|c|c|c|c|c|c|c|}
\hline & Answer 1 & Answer 2 & Answer 3 & Answer 4 & Answer 5 & Answer 6 & Answer 7 & Answer 8 & Answer 9 \\
\hline Houldin (2007) [30] & Yes & Yes & No & $?$ & $?$ & No & Yes & $?$ & Yes \\
\hline Paiva et al. (2012) [31] & Yes & Yes & No & Yes & $?$ & No & Yes & Yes & Yes \\
\hline Plank et al. (2012) [32] & Yes & Yes & Yes & Yes & Yes & $?$ & Yes & Yes & Yes \\
\hline Grimmer et al. (2004) [36] & Yes & Yes & No & No & $?$ & No & Yes & No & Yes \\
\hline Teschendorf et al. (2007) [41] & Yes & Yes & No & Yes & $?$ & No & $?$ & $?$ & $?$ \\
\hline Shaw et al. (2013) [33] & Yes & Yes & No & Yes & $?$ & $?$ & Yes & $?$ & Yes \\
\hline Smith et al. (2004) [35] & Yes & Yes & No & Yes & Yes & $?$ & Yes & Yes & Yes \\
\hline Greenwood et al. (2009) [40] & Yes & Yes & No & No & $?$ & No & Yes & Yes & Yes \\
\hline Bakas et al. (2002) [39] & Yes & Yes & No & $?$ & $?$ & No & Yes & $?$ & Yes \\
\hline Weng et al. (2011) [42] & Yes & Yes & No & $?$ & Yes & $?$ & Yes & $?$ & Yes \\
\hline Silva-Smith (2007) [43] & Yes & Yes & No & $?$ & $?$ & No & Yes & Yes & $?$ \\
\hline Brereton and Nolan (2002) [45] & Yes & Yes & Yes & Yes & $?$ & No & Yes & Yes & Yes \\
\hline Shyu (2000) [46] & Yes & Yes & No & Yes & Yes & $?$ & Yes & Yes & Yes \\
\hline Rodrigues et al. (2013) [44] & Yes & Yes & $?$ & Yes & $?$ & No & Yes & No & Yes \\
\hline Pereira and Rebelo-Botelho (2011) [38] & Yes & Yes & $?$ & Yes & Yes & $?$ & Yes & $?$ & Yes \\
\hline Nahm et al. (2010) [37] & Yes & Yes & No & $?$ & Yes & No & Yes & No & $?$ \\
\hline Abrahamson (2016) & Yes & Yes & Yes & Yes & Yes & No & Yes & Yes & Yes \\
\hline Giosa et al. (2014) [47] & Yes & Yes & Yes & Yes & Yes & No & Yes & Yes & Yes \\
\hline Moral-Fernández et al. (2018) [29] & Yes & Yes & No & Yes & Yes & No & Yes & Yes & Yes \\
\hline Yes & 19 & 19 & 4 & 12 & 9 & 0 & 18 & 10 & 16 \\
\hline $\mathrm{No}+?$ & 0 & 0 & 15 & 7 & 10 & 19 & 1 & 8 & 3 \\
\hline No & 0 & 0 & 13 & 2 & 0 & 13 & 0 & 3 & 0 \\
\hline$?$ & 0 & 0 & 2 & 5 & 10 & 6 & 1 & 5 & 3 \\
\hline
\end{tabular}

put up a barrier. I sort of just try to look at it as if it's not my husband. ... Learning to separate yourself from the patient. You get so emotionally involved.' [41].

\section{Beginning to realise}

Following the assumption of the role and the changes produced, and once in the home, family caregivers begin

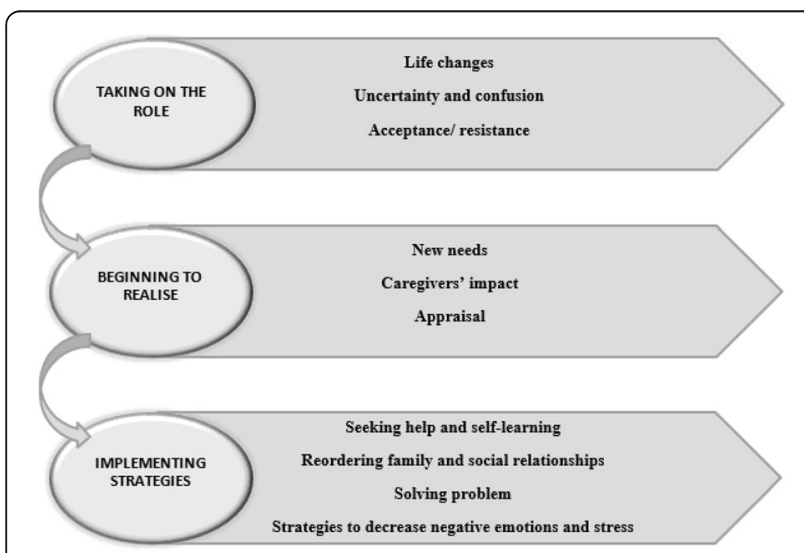

Fig. 3 Diagram of the process of becoming suddenly a caregiver of a dependent older relative to realise what the care of their relative entails for their own lives. They begin to be aware of the situation of dependency of their family member, which they sometimes compare with young children, and the amount of care they require for, where possible, an improvement to occur $[31,32]$.

\section{Carers' impact}

With the development of caregiving, family caregivers begin to realise the difficulty of this task and the responsibility for be the well-being of their relative being in their hands. Many areas of their lives are altered as a result of their work as a caregiver, starting with their own personal life [33, 38]. 'We lost our personal life... most of it depends on my mother's schedule. For us, being still young, it's hard' [38].

The performance of so many activities, with the reconciliation of their lives up to the present, presents a challenge to them, causing them stress, weight, and anxiety [29, 32, 37-39, 42]. 'I have been diagnosed with anxiety. I am nervous and get angry easily. The stress comes from inside myself and causes me to feel tremendous tension. This is a difficult time for me' [42]. 
The difficulty in combining so many activities is also due to a lack of time. Continuous supervision of a relative is a great time constraint $[29,35,43]$.

As a result of the development of care and restrictions of their time, some family caregivers have repercussions in their working life, and even have to leave their paid work in order to dedicate themselves to the care of their family member: 'End up abandoning my job, because there was nobody to care for my mother' [44]. This, together with the economic impact of the development of an elderly person in a situation of dependency, also causes their economic situation to be negatively impacted [29, 35, 39-41, 43].

They do not have time for themselves, they cannot do the same activities they used to do, and even their sleep is affected, either because of concerns about the care situation and their family, or the person's needs for attention [29, 30, 32, 37, 40]. 'I'm sleeping less and less, because of all the problems regarding appropriate home environment' [32].

This lack of sleep also affects the physical state of the caregiver, in addition to the mental state, which causes daily fatigue and exhaustion [29, 33, 37, 39, 41, 45]. 'I'm getting tired. 'Cause I need a holiday...I'm just a bit tired, emotionally drained actually' [33].

Their social life is largely non-existent because they have to spend so much time taking care of their relative. Moreover, relationships between the dependent family member and the caregiver's nuclear family are affected in this situation, especially in the early stages, because there is a loss of privacy for the family or couple, which can cause family conflict $[29,30,38,39,43,45]$. ' $\mathrm{He}$ never complained of anything, and suddenly he fell in the bathroom, it was such a fright... this situation had an impact on the family relationships, because of his limitations' [44].

It is also worth mentioning that there are also discourses in which caregivers mention the personal growth and satisfaction that the care task reports to them, and how it helps them value day-to-day things [29, 40, 41]. 'You appreciate a lot of things, don't you when you can't do all the things you did? So I think you learn to know yourself a lot better... and then you think 'I can'... and there is a certain satisfaction, isn't there?' [40].

\section{New needs}

The synthesis of the findings found in the articles on the first moments in the care of a dependent family shows that the main needs of the initial caregivers are the need for information, time, help, support, and instruction for care.

The need for information about the illness, care and prognosis of the family member, and the training to develop the necessary skills to perform the task of caring in the best possible way, is reflected in the requests of family caregivers to health personnel $[29,30,32,33,35-$ 37, 39-41, 43, 45-47]. 'We would like to know how ill she is; I think the hospital should give us a card and state what kind of disease the patient has, how well the disease has been treated, and whether there are any risks left, so the family can know what to expect.' [46].

They emphasise expressions like, 'there was nobody there that could tell me,' 'no one tells you anything,' nobody really told me anything, from which the presence of personnel is glimpsed, without any offer of information or help.

They do not feel sufficiently prepared to take care of their relative with all the problems that the patient may present at any time [34, 41, 42, 47].

Caregivers also complain about the need for financial resources, because caring for a dependent person entails a lot of expenses and they do not normally have a paid job, or as stated in the previous category, they have had to leave a job because of the care $[29,35,46]$.

They find it difficult to balance care with their other responsibilities, and for this reason they express that aid is one of the most important needs, whether at the professional level, by health personnel; or family, in many cases no other family member is involved in care [32, 33, 43, 45].

Family caregivers not only do not receive help in caring for their relatives, they do not receive support for themselves. Hence they express the need for someone to go and see them and talk to them to get their act together [29, 38, 46]. 'I feel like I am in a room with thousands of people and I am screaming out and no one is hearing me.' [43].

\section{Appraisal}

According to Lazarus and Folkman [48], appraisal is a process by which a person evaluates the situation and makes changes in his or her behaviours or skills needed to cope with the stressful situation. In this case, family caregivers generally feel that they cannot cope with this task properly and need help in their functions and resources to continue in the right way [33, 36, 45]. 'It really battered me around... it really wears you down. I couldn't cope I had to get out...I'm tired of it.' [35].

\section{Implementing strategies}

After assuming the role of caregiver and beginning to realise the consequences, caregivers try to adopt certain strategies that make this task of care more bearable for them.

\section{Seeking help and self-learning}

Among these strategies adopted, caregivers try to learn about the disease that affects their family and the 
dispensing of care required, thus seeking both formal and family help, and they try to learn care skills [36, 40, $45,47]$. 'I started reading a lot about what to expect. .. so I tried to understand what she is going to be changing into' [40]. "We were pulling it [looking for information] on our own because otherwise it was just a black hole... you're kind of thirsting for information that whole time" [47].

\section{Reordering family and social relationships}

As stated earlier, one of the consequences of taking on the carer role is the changing of their social and family relationships, so that caregivers seek to reorganise these relationships to normalise the situation. Thanks to this family organisation, the work is done as a routine that is divided into jobs for each member of the family, which creates a greater sense of family calm $[40,43]$. 'I think that we're calming down, I can feel this too, I myself am much calmer! But I still think the insecurity affects us because it's all very new, you know? However, I feel, like my sisters, that we're restructuring...it's because time is passing.' [43].

\section{Solving problems}

Following trying to normalise the situation of care, caregivers may adopt coping strategies focused on solving problems, which increases safety in the care they provide $[29,38,40]$. 'I think that every time we get a little bit further away, it makes us more secure. It is like dangerous waters and we are gradually sailing out of them' [40].

\section{Strategies to decrease negative emotions and stress}

Finally, in the process of becoming a caregiver, they seek to reduce the negative effects by trying to take care of strategies to maintain emotional positivity and reduce stress levels such as talking to the family and letting go, taking things intentionally humorously, being positive and optimistic, and encouraging the person cared for to maintain spiritual support, among others [30, 31, 40]. 'One thing that - whatever happens, I always say that it is [the] best. Better. God never wants to harm you, it is your destiny. And there is always something positive good.' [40].

\section{Discussion}

The findings of the present metasynthesis respond to the objective proposed in the research and show that the process by which people suddenly become caregivers of an elderly relative in a situation of dependence is dynamic and progressive in time. It happens when a family member develops symptoms that make it difficult to carry out the activities of his daily life, and a person from his family environment helps him with the care needs that arise, until this person who takes on the caregiver's role begins to realise the consequences and tries to normalise his new role of caregiver.

There is no article that indicates the generic phases through which a caregiver passes to take care of a dependent family suffering an acute-onset illness, but we found articles that describe stages of this transition in dementia $[15,17,18]$, research about the stages towards cohabitation [16], the process of adaptation to dependency in older adults and their families [49], some theoretical approaches [13], and another review about family care in terminally ill patients [50]. Firbank and Johnson [16], examine the paths that lead elderly people and their family caregivers to cohabiting. Bunn et al. [15] evaluate the qualitative evidence about how people accommodate and adapt to the diagnosis of dementia and its immediate consequences. Prorok et al. [18] try to understand the health-care experience of people with dementia and their carevigers. Gibbons et al. [17] try to understand the experience of family caregivers during the liminality phase. Finally, Martín et al. [50] reveal the experience of family caregivers who care for a terminally ill patient in their home. The results of these studies coincide roughly with our results, so that Firbank and Johnson [16], Bunn et al. [15], Gibbons et al. [17], and Martín et al. [50] first identified a health event that causes some kind of dependency in a family, which means that a family member takes over care, hence after diagnosis, the stage of change begins.

A common event in all phases of research dedicated to the process of becoming a caregiver is the changes. This research shows that the trigger with which the process of becoming a caregiver begins is the great change caused by a dependence situation in a family member. This is widely supported with various studies. Bunn et al. [15] and Moreno-Cámara et al. [11] describe these changes in a way that is similar the present research; during the first phase of care, when the family has been diagnosed with dementia and begins with a succession of changes that interfere with all areas of the lives of the caregiver, and to which they must adapt. Gibbons et al. [17], speaks about a pivotal event (disability or illness) in the pre-liminal phase that turns the lives of caregivers upside down and causes changes in the intermediate stage of care; in particular they highlight social changes. Prorok et al. [18] agree with our results that identify confusion and uncertainty early in the process, and identify changes in the last phase of the start of care, in which the caregiver must live with these changes. Changes are also a constant in most of the research on the early stages of care $[9,50-55]$. In spite of 'change' being a category as such individually, it is also the precursory of other categories and influences in the development of them, not only because of its meaning but because all other categories that make up the process of 
becoming a caregiver happen with subsequent changes. For this reason, it is a dimension identified in the early stages of care.

In this first phase of assuming the role of caregiver, a range of emotions experienced by carers will accompany the changes, highlighting the uncertainty and suffering that coincide with those expressed by Gibbons et al. [17] in the liminal and post-liminal phase in their research about the beginning of caring, and by Moreno et al. [11]. These emotions have also consistently surfaced in several original studies and reviews about the beginning stage of care $[54,56]$ and they are widely developed in the studies of this metasynthesis, from comforting and satisfying emotions to emotions of fear and despair.

In the second stage, caregivers begin to realise their new role. In this way, new needs arise that are associated with the care of their relative, and they start to experience the consequences of exercising this role. The results of this metasynthesis resemble those found in Prorok's article [18], which identifies the need for information during the early stages of care, Bunn's article [15], which also describes the second phase of the start of care as a time when conflicts arise, and Firbank's research [16], which explains the elderly person's inability to perform activities of daily living and the children's needs in providing help to their parent. Also, the needs that emerge in the early stages of caring are matched in studies of caregivers of people who have had a stroke $[56,57]$, and the consequences coincide, to a large degree, with the results most commonly found in other research into the early stages of care $[55,58,59]$.

During the third phase, which involves implementation of strategies to minimise the negative effects of care, the emotional consequences and stress occur. Caregivers seek to learn the skills to become more self-sufficient in care and finally reorganise relations for a better adaptation of both the family and social situation. Among these implemented strategies we can find coping strategies, which include seeking help and solving the problems that arise during care. The latest strategy is, according to Gottlieb and Wolfe [60], the most important and better coping strategy. This coincides roughly with the third stage proposed by Bunn et al. [15] where, as in this metasynthesis, the implementation of strategies that help to minimise the impact of care was located after the initial changes, and with Prorok's [18] and Moreno-Cámara's research [11], identifying self-learning as also being an important strategy of implementation. All these facts mark a new situation of normality for the family caregiver [17, 48], thus showing a sample of acceptance and normalization of her new role and culminating the process of conversion to caregiver.

It is interesting how significant differences were not found in relation to the different pathologies that the dependent person suffered, but to their level of dependence and the abilities of the caregiver to develop adequate coping strategies. The phases proposed in this research can be related to the common phases of a crisis, referred to as 'a temporary event with a start and an end that appears unexpectedly and whose course follows the following phases: impact phase, reaction phase and phase of reorientation' ([61] p. 51). In agreement with the results of the present research and the phases proposed by Ruiz [61], it could be determined that the people who become caregivers at first are impacted due to the unexpected character of their new role, stunning him and affecting him emotionally. This could correspond to a state of shock, which is characterised by a state of shock and blockage. The reaction phase is related to the awareness of the situation, which implies suffering and different emotional reactions. After that, the reorientation phase is characterised by the assimilation of the situation, whereby the caregiver begins to accept what has happened and is mobilised to face and overcome the situation, producing in this way a readjustment in their lives in search of a new stability.

The results of this metasynthesis help us to understand how a relative takes care of a dependent elderly person and how this care evolves until the caregiver begins to adapt to this role. Knowing the stages of the process of becoming a caregiver may be useful for health professionals in establishing interventions tailored to each stage in order to help caregivers to adapt to their new role and resolve their uncertainty and inexperience.

Because the first moments of care have a common succession of changes triggered after diagnosis, which causes feelings of confusion, suffering, and uncertainty, early interventions might be appropriate based on generic information about the disease that has led to the dependence of the older person, the care needs during the first moments of care, and information about available resources, in order to alleviate feelings of confusion and uncertainty experienced by caregivers. During the second and third stages, caregivers evaluate the caring situation and implement strategies to adapt to the caring situation; at this time, tailored interventions are needed to help caregivers in assuming their role, implementing better adaptive strategies, and solving care needs.

\section{Limitations}

The main limitation of this research is the lack of availability of the complete original transcripts of the primary studies, which hinders and influences the researchers' analysis of this metasynthesis. This research is based on fragments of caregiver discourses that the primary authors have selected as a reflection of their results. To try to solve this limitation, two different researchers have analyzed the discourses 
independently and unrelated to the interpretation of the original authors.

With respect to the quality of the studies included in metasynthesis, a good quality of the included studies has generally been observed. According to the CASP tool, a large number of responses are positive, although criteria related to the justification of the research design in relation to the aims of the research, the explanation of the data collection and the consideration of the relationships between the researcher and the study participants. Although the first two criteria are evaluated in a deficient manner, it is possible to observe the congruence of designs and data collection methods used in the included studies with the analysis of the initial experiences of persons who suddenly become caregivers for elderly dependent relatives, even though these issues are not specifically detailed in most of the articles of the present review. Thus, it would have a minimal impact of the low quality in the previous criteria on the review's quality. This possible minimal impact is based not only in previous reasoning but also in the assertion of Sandelowski and Barroso, which argued that the quality of the studies should not determine the integrity of the research [19].

\section{Transferability}

The analysis of qualitative information included in this metasynthesis, which comes from different cultural contexts and various caregiver profiles, means these results are useful for understanding the earliest stages of care for dependent elderly family members in different situations.

In addition, both the search strategy and the characteristics of each included study have been described in detail, which allows its replication, and may facilitate transferability to other similar situations.

\section{Conclusions}

The main contribution of this study is the identification of the process characterised through the stages of 'taking on the role', 'beginning to realise', and 'implementing strategies'. At the beginning stage of caring for a dependent family member, it is usual for the caregiver to experience changes that affect most aspects of the caregiver's life, such as the responsibilities they assume and the activities they must perform once they become carers. As they have to perform all the activities and meet all the needs that the patient cannot do for themselves, there is an increase in their own needs that is provoked by the new situation that they have to deal with regarding their caring role. All this entails some consequences for the caregiver, which often tend to be emotional, familial, and social. Finally, the carer of an elderly person who becomes dependent suddenly seeks strategies to normalise their situation as caregiver and reduce stress.
This study will allow us to learn more about the transition to the role of caregiver in order to propose a more detailed plan of care, with specific interventions during the early days of caring. Early interventions based on generic information may be needed at the beginning of the process in order to alleviate uncertainty, and tailored interventions may be needed later, depending on the evaluation of the caring situation, in order to help caregivers with implementing adaptive strategies.

We recommend that future research should include the development of studies that address the process of becoming a primary caregiver as a phenomenon of global study with primary data.

\section{Abbreviations}

CASP: Critical appraisal skills programme; Gl cancer: Gastrointestinal cancer; MeSH: Medical subject headings; TBI: Traumatic brain injury

\section{Funding}

This research received no specific grant from any funding agency in the public, commercial, or not-for-profit sectors.

\section{Availability of data and materials}

All data generated or analysed during this study are included in this published article [and its Additional files].

\section{Authors' contributions}

All authors have agreed on the final version and they were responsible for the conception and design of the study. MF, FO, MC, PM and DPC performed the collection of data, data analysis and interpretation by consensus. MF and FO were responsible for the drafting of the manuscript. MF, FO, MC, PM and DPC made critical revisions to the article for important intellectual content.

Ethics approval and consent to participate

This is a systematic review and evidence synthesis of qualitative research. As such, it involves secondary data analysis of published material and does not require ethics committee approval.

Consent for publication

Not applicable.

Competing interests

The authors declare that they have no competing interests.

\section{Publisher's Note}

Springer Nature remains neutral with regard to jurisdictional claims in published maps and institutional affiliations.

Received: 7 February 2017 Accepted: 16 September 2018

Published online: 25 September 2018

\section{References}

References marked with an asterisk indicate studies included in the metasynthesis. The in-text citations to studies selected for metasynthesis are not preceded by asterisks

1. United Nations, Department of Economic and Social Affairs, Population division. World population ageing 2013. New York: United Nations; 2013.

2. Confederation of Family Organisations in the European Union. Charter for Family Carers. 2011. http://www.coface-eu.org/wp-content/uploads/2017/ 01/COFACE-Disability-CharterEN.pdf. Accessed 24 Jan 2017.

3. Verbakel E. How to understand informal caregiving patterns in Europe? The role of formal long-term care provisions and family care norms. Scand J Public Health. 2017 1. [Epub ahead of print]. 
4. Macleod M, Chesson RA, Blackledge P, Hutchison JD, Ruta N. To what extent are carers involved in the care and rehabilitation of patients with hip fracture? Disabil Rehabil. 2005;27(18-19):1117-22.

5. Schulz R, Sherwood PR. Physical and mental health effects of family caregiving. Am J Nurs. 2008;108(9 Suppl):23-7. https://doi.org/10.1097/01. NAJ.0000336406.45248.4C.

6. Brewin A. The quality of life of carers of patients with severe lung disease. Br J Nurs 2004 08/12; 13(15):906-912.

7. van Vliet D, de Vugt ME, Bakker C, Koopmans RTCM, Verhey FRJ. Impact of early onset dementia on caregivers: a review. Int J Geriatr Psychiatry. 2010; 25(11):1091-100

8. Rolland J. Families, illness and disability. New York: Basic Books; 1994.

9. Covelli V, Cerniauskaite M, Leonardi M, Sattin D, Raggi A, Giovannetti AM. A qualitative study on perceptions of changes reported by caregivers of patients in vegetative state and minimally conscious state: the "time gap experience". Sci World J. 2014;2014:1-9.

10. Ducharme F, Lévesque L, Lachance L, Kergoat MJ, Coulombe R. Challenges associated with transition to caregiver role following diagnostic disclosure of Alzheimer disease: a descriptive study. Int J Nurs Stud. 2011;48(9):1109.

11. Moreno-Cámara S, Palomino-Moral PA, Moral-Fernández L, Frías-Osuna A, del-Pino-Casado R. Problemas en el proceso de adaptación a los cambios en personas cuidadoras familiares de mayores con demencia [problems in the process of adapting to change among the family caregivers of elderly people with dementia]. Gac Sanit. 2016;30(3):201-7.

12. Perren S, Schmid R, Wettstein A. Caregivers' adaptation to change: the impact of increasing impairment of persons suffering from dementia on their caregivers' subjective well-being. Aging Ment Health. 2006;10(5):539-48.

13. Montgomery R, Kosloski K. Caregiving as a process of changing identity: implications for caregiver support. Generations. 2009;33(1):47-52.

14. Schumacher $\mathrm{KL}$, Jones PS, Meleis Al. Helping elderly people in transition: a framework for research and practice. In: Swanson EA, Tripp-Reimer T, editors. Life transitions in the older adult. Issues for nurses and other health professionals. New York: Springer; 1999. p. 1-23.

15. Bunn F, Goodman C, Sworn K, Rait G, Brayne C, Robinson L, et al. Psychosocial factors that shape patient and carer experiences of dementia diagnosis and treatment: a systematic review of qualitative studies. PLoS Med. 2012;9(10):e1001331. https://doi.org/10.1371/journal.pmed.1001331.

16. Firbank $O E$, Johnson-Lafleur J. Older persons relocating with a family caregiver: processes, stages, and motives. J Appl Gerontol. 2007;26(2):182-207.

17. Gibbons SW, Ross A, Bevans M. Liminality as a conceptual frame for understanding the family caregiving rite of passage: an integrative review. Res Nurs Health. 2014;37(5):423-36.

18. Prorok JC, Horgan S, Seitz DP. Health care experiences of people with dementia and their caregivers: a meta-ethnographic analysis of qualitative studies. CMAJ. 2013;185(14):E669-80. https://doi.org/10.1503/cmaj.121795.

19. Sandelowski M, Barroso J. Handbook for synthesizing qualitative research. New York: Springer; 2006.

20. McKibbon AK, Wilczynski NL, Haynes RB. Developing optimal search strategies for retrieving qualitative studies in PsyCinfo. Eval Health Prof. 2006;29(4):440-54.

21. Evans D. Database searches for qualitative research. J Med Libr Assoc. 2002; 90(3):290-3.

22. Critical Appraisa Skills Programme. CASP Qualitative Checklist. 2018. https:// casp-uk.net/wp-content/uploads/2018/01/CASP-Qualitative-Checklist.pdf. Accessed 16 July 2017.

23. Walsh D, Downe S. Meta-synthesis method for qualitative research: a literature review. J Adv Nurs. 2005:50(2):204-11.

24. Whittemore R, Knafl K. The integrative review: updated methodology. J Adv Nurs. 2005;52(5):546-53.

25. Glaser BG. Theoretical sensitivity. Mill Valley: Sociology Press; 1978.

26. Glaser BG, Strauss AL. Discovery of grounded theory. Mill Valley: Sociology Press; 1967.

27. Strauss A, Corbin J. Bases de la investigación cualitativa. Técnicas y procedimientos para desarrollar la Teoría Fundamentada. Antioquía: Universidad de Antioquía; 2002.

28. Maxwell J. Understanding and validity in qualitative research. Harv Educ Rev. 1992;62(3):279-301.

29. Moral-Fernández L, Frías-Osuna A, Moreno-Cámara S, Palomino-Moral PA, Del-Pino-Casado R Primeros momentos del cuidado: el proceso de convertirse en cuidador de una familiar mayor dependiente. Aten Primaria. 2018;50(5):282-90
30. *Houldin A. A qualitative study of caregivers' experiences with newly diagnosed advanced colorectal cancer. Oncol Nurs Forum. 2007:34(2):323-30.

31. *Paiva $R$, Valadares $G$, Silva J. The need to become family caregivers: grounded theory. OBJN. 2012;11(3):607-620.

32. *Plank A, Mazzoni V, Cavada L. Becoming a caregiver: new family carers' experience during the transition from hospital to home. J Clin Nurs. 2012; 21(13-14):2072-82. doi:https://doi.org/10.1111/j.1365-2702.2011.04025.x.

33. *Shaw J, Harrison J, Young J, Butow P, Sandroussi C, Martin D, Solomon M. Coping with newly diagnosed upper gastrointestinal cancer: a longitudinal qualitative study of family caregivers' role perception and supportive care needs. Support Care Cancer. 2013;21(3):749-56.

34. *Abrahamson JJ, Jensen J, Springett K, Sakel M. Experiences of patients with traumatic brain injury and their carers during transition from inpatient rehabilitation to the community: a qualitative study. Disabil Rehabil. 2017; 39(17):1683-94.

35. *Smith LN, Lawrence M, Kerr SM, Langhorne P, Lees KR. Informal carers' experience of caring for stroke survivors. J Adv Nurs. 2004:46(3):235-44. doi: https://doi.org/10.1111/j.1365-2648.2004.02983.x.

36. ${ }^{*}$ Grimmer K, Moss J, Falco J. Becoming a carer for an elderly person after discharge from an acute hospital admission. IJAHSP. 2004;2(4):4.

37. *Nahm ES, Resnick B, Orwig D, Magaziner J, DeGrezia M. Exploration of informal caregiving following hip fracture. Geriatr Nurs. 2010;31(4):254-62.

38. *Pereira HR, Botelho MA. Sudden informal caregivers: the lived experience of informal caregivers after an unexpected event. J Clin Nurs. 2011;20(1718):2448-57. doi:https://doi.org/10.1111/j.1365-2702.2010.03644.x.

39. *Bakas T, Austin J, Okonkwo K, Lewis R, Chadwick L. Needs, concerns, strategies and advice of stroke caregivers the first 6 months after discharge. JNeurosci Nurs. 2002:34(5):242.

40. ${ }^{*}$ Greenwood N, Mackenzie A, Cloud GC, Wilson N. Informal primary carers of stroke survivors living at home - challenges, satisfactions and coping: a systematic review of qualitative studies. Disabil Rehabil. 2009;31(5):337-51.

41. *Teschendorf B, Schwartz C, Ferrans CE, O'Mara A, Novotny P, Sloan J. Caregiver role stress: when families become providers. Cancer Control. 2007; 14(2):183-9.

42. *Weng L, Huang H, Wang Y, Chang C, Tsai C, Lee W. Primary caregiver stress in caring for a living-related liver transplantation recipient during the postoperative stage. J Adv Nurs. 2011;67(8):1749-57. doi:https://doi.org/10. 1111/j.1365-2648.2011.05625.x.

43. *Silva-Smith AL. Restructuring life preparing for and beginning a new caregiving role. J Fam Nurs. 2007;13(1):99.

44. *Rodrigues RA, Marques S, Kusumota L, Barros E, da Silva JR, Coelho SC. Transition of care for the elderly after cerebrovascular accidents: from hospital to the home. Rev Lat Am Enfermagem. 2013;21(spe):216-24.

45. *Brereton L, Nolan M. 'Seeking': a key activity for new family carers of stroke survivors. J Clin Nurs. 2002;11(1):22-31. doi:https://doi.org/10.1046/j.13652702.2002.00564.X

46. *Shyu YIL. The needs of family caregivers of frail elders during the transition from hospital to home: a Taiwanese sample. J Adv Nurs. 2000;32(3):619-25.

47. *Giosa J, Stolee P, Dupuis S, Mock S, Santi S. Experiences during care transitions of older adults. Canadian Journal on Aging. 2014;33(2):137-53.

48. Lazarus RS, Folkman S. Stress, appraisal and coping. New York: Springer; 1984.

49. Abad-Corpa E, Gonzalez-Gil T, Martínez-Hernández A, Barderas-Manchado AM, De la Cuesta-Benjumea C, Monistrol-Ruano O, et al. Caring to achieve the maximum independence possible: a synthesis of qualitative evidence on older adults' adaptation to dependency. J Clin Nurs. 2012:21(21-22):3153-69.

50. Martín J, Olano-Lizarraga M, Saracíbar-Razquin M. The experience of family caregivers caring for a terminal patient at home: a research review. Int J Nurs Stud. 2016:64:1-12.

51. Lin H, Lin H, Lin W. Middle-aged female spouses of patients with metastatic cancer: lived experiences. J Nurs Res. 2015;23(2):135-44.

52. McConigley R, Halkett G, Lobb E, Nowak A. Caring for someone with high-grade glioma: a time of rapid change for caregivers. Palliat Med. 2010;24(5):473-9.

53. Pringle J, Hendry C, McLafferty E. A review of the early discharge experiences of stroke survivors and their carers. J Clin Nurs. 2008;17(18):2384-97.

54. Seal K, Murray CD, Seddon L. The experience of being an informal 'carer' for a person with cancer: a meta-synthesis of qualitative studies. Palliat Support Care. 2015:13(03):493-504

55. Nalder E, Fleming J, Cornwell P, Foster M. Linked lives: the experiences of family caregivers during the transition from hospital to home following traumatic brain injury. Brain Impair, Special Issue. 2012;13(01):108-22. 
56. Cecil R, Thompson K, Parahoo K, McCaughan E. Towards an understanding of the lives of families affected by stroke: a qualitative study of home carers, J Adv Nurs. 2013;69(8):1761-70.

57. Ågård AS, Egerod I, Tønnesen E, Lomborg K. From spouse to caregiver and back: a grounded theory study of post-intensive care unit spousal caregiving. J Adv Nurs. 2015;71(8):1892-903.

58. Bocchi SCM. Vivenciando a sobrecarga ao vir-a-ser um cuidador familiar de pessoa com acidente vascular cerebral (AVC): Análise do conhecimento. Revista Latino-Americana de Enfermagem. 2004;12(1):115-21.

59. Turner B, Fleming J, Cornwell P, Worrall L, Ownsworth T, Haines T, Kendall $\mathrm{M}$, Chenoweth L. A qualitative study of the transition from hospital to home for individuals with acquired brain injury and their family caregivers. Brain Inj. 2007;21(11):1119-30.

60. Gottlieb BH, Wolfe J. Coping with family caregiving to persons with dementia: a critical review. Aging Ment Health. 2002;6(4):325.

61. Ruiz CR. Apoyo psicológico en situaciones de emergencia. SA: Ediciones Paraninfo; 2017

Ready to submit your research? Choose BMC and benefit from:

- fast, convenient online submission

- thorough peer review by experienced researchers in your field

- rapid publication on acceptance

- support for research data, including large and complex data types

- gold Open Access which fosters wider collaboration and increased citations

- maximum visibility for your research: over $100 \mathrm{M}$ website views per year

At BMC, research is always in progress.

Learn more biomedcentral.com/submissions 